\title{
An Overview of the Removal Phosphorus in Wastewater
}

\section{Norwardatun Abd Roni ${ }^{1}$, Suraya Hani Adnan ${ }^{1 *}$, Nuramidah Hamidon ${ }^{1}$, Tuan Noor Hasanah Tuan Ismail ${ }^{1}$}

\author{
${ }^{1}$ Department of Civil Engineering Technology, Faculty of Engineering Technology \\ Universiti Tun Hussein Onn Malaysia, 84600 Pagoh Branch, Muar, Johor, MALAYSIA \\ *Corresponding Author
}

DOI: https://doi.org/10.30880/ijie.2020.01.02.001

Received 18 June 2020; Accepted 07 September 2020; Available online 15 December 2020

\begin{abstract}
The high levels of phosphorus (P) removal occurring through human activities contributes to Eutrophication. Therefore, it is important to understand the quantity of $\mathrm{P}$ flows of the different filter materials. This paper provides an overview on the different filter media used for $\mathrm{P}$ removal from wastewater also the conventional wastewater treatment system for phosphorus removal. The filter materials consist of natural materials, industrial by-products and man-made products. Most filters have been investigated in batch and column studies in laboratory. The results from these overview vary for every filters and recycled concrete aggregates (RCA) have demonstrated promising properties with regard to $\mathrm{P}$ removal capacity. The chemical composition of the adsorption media is a critical factor. Because phosphorus is removed via sorption and precipitation processes, Calcium (Ca), Iron (Fe) and Aluminium (Al) content is important in efficient $\mathrm{P}$ removal. Thus filter media should be selected very carefully. In such systems, appropriate pre-treatment will also allow for a longer lifetime of the filter media, by decreasing the risk of clogging and allowing one to use finer reactive filter media with higher sorption capacity. The usage of these alternatives filters materials will ease the environmental problems that are currently perceived globally.
\end{abstract}

Keywords: Filter, phosphorus, wastewater, batch, column

\section{Introduction}

Phosphorus is an important nutrient constituent for aquatic plant growth in the natural water system. However, excessive phosphorus loads in water bodies due to industrial, agricultural and household wastes might cause the overgrowth of aquatic plants or algae. This will accelerate the depletion of dissolved oxygen (DO) in water and lead to eutrophication. Hence, strict effluent quality standards for wastewater treatment plants (WWTPs) are implemented by governments all over the world. (Keeley et al., 2016). Municipal wastewaters comprehend from 5 to $20 \mathrm{mg} / \mathrm{L} \mathrm{of} \mathrm{total}$ phosphorus, of which 1-5 mg/l are organic and the rest are inorganic (Henze and Ledin, 2018). Phosphorus is one of the main constituents of synthetic detergents. The individual phosphorus impact varies between 0.65 and $4.80 \mathrm{~g} / \mathrm{inhabitant}$ per day with an average of about $2.18 \mathrm{~g}$. Generally, secondary treatment can only remove 1-2 mg/L of phosphorus, so excess phosphorus is often discharged in the final effluent and causes eutrophication in surface water (Han et al., 2016). Bowman et al., (2018) found that the addition of phosphorus in the range of even 0.1-5.6 $\mu / \mathrm{L}$ over a long period might activate algal blooms in part of a natural lake. Therefore, removal of phosphorus is very essential either it can be rehabilitated into a particulate form or removed as a particulate by sedimentation or filtration using membrane treatment. The most regularly used method for phosphorus removal from wastewater is chemical precipitation and this method is able to reduce the concentration of phosphorus to values below $1 \mathrm{mg} / \mathrm{L}$ in sewage treatment plants (Morse $e t$ al., 2018).Nevertheless, chemical precipitation is expensive in many parts of the world and it might produce new 
pollutants such as chloride and sulphate (Altundogan and Tumen, 2016). In addition, it also requires the disposal for the precipitate formed and neutralisation of the treated effluent.

There is a dual concern regarding nutrients, since they contribute to unfavourable health and environmental effects thus their control is imperative, but the same nutrients are essential for the performance of the natural biological treatment system. Eutrophication is a process of an increase in the biological productivity of a body of water as a result of nutrient enrichment. Nutrients, especially nitrogen and phosphorus, can stimulate and create favourable conditions for the growth of toxin-producing cyanobacteria which can cause detrimental consequences to human. Eutrophication can lead to low dissolved oxygen levels, interference with recreational uses of water and drinking water taste, and results in summer blooms of undesirable blue-green algae. Also, it can promote undesirable changes in aquatic populations and induce health risks to humans and livestock (Akpor \& Muchie, 2017). Therefore, both nutrients should be considered in the efforts of managing eutrophication (Dodds \& Smith, 2016). Hence, the main aim of this paper are to study the conventional wastewater treatment system for phosphorus removal and the various filter media for phosphorus removal.

\subsection{Conventional Wastewater Treatment System for Phosphorus Removal}

The biological removal of phosphorus and chemical precipitation are communal conventional wastewater treatment systems for the removal of phosphorus (Ramasahayam et al., 2014). This treatment is beneficial and and meets the discharge standards of effluents (Khiewwijit, 2016). Conversely, Mara (2013) recommended that conventional systems must only be used for very huge populations with great caution as it consumes a lot of electricity. Furthermore, expert workers are required for maintaining and operating the complex treatment system.

\subsection{Chemical Precipitation}

Chemical precipitation is a well-known and attractive choice because of its simple operation and implementation (Water Environment Federation, 2011). Chemical precipitation occurs when divalent or trivalent metal salts encounter soluble phosphate in wastewater to form solid precipitates of metal phosphates. The metal salts used are salts containing $\mathrm{Al}^{3+}, \mathrm{Fe}^{2+}, \mathrm{Fe}^{3+}$, and $\mathrm{Ca}^{2+}$ (Wang et al., 2015). Moreover, they are also involved in sorption or coprecipitation with orthophosphate. The solids formed can be removed by solid separation processes including clarification, sedimentation and filtration.

Chemical precipitation can be used during several stages of wastewater treatment; before primary sedimentation (primary precipitation), during the activated sludge process (secondary precipitation), or after secondary treatment (tertiary precipitation) (Morse et al., 2018). Figure 1 shows potential Fe and P interactions at different stages where Fe salts can be treated at various stages to initiate phosphorus removal. Wilfert et al., (2015) stated that Fe salts react with phosphorus and undergoes the redox reaction to produce insoluble $\mathrm{Fe}^{3+}$ phosphate.

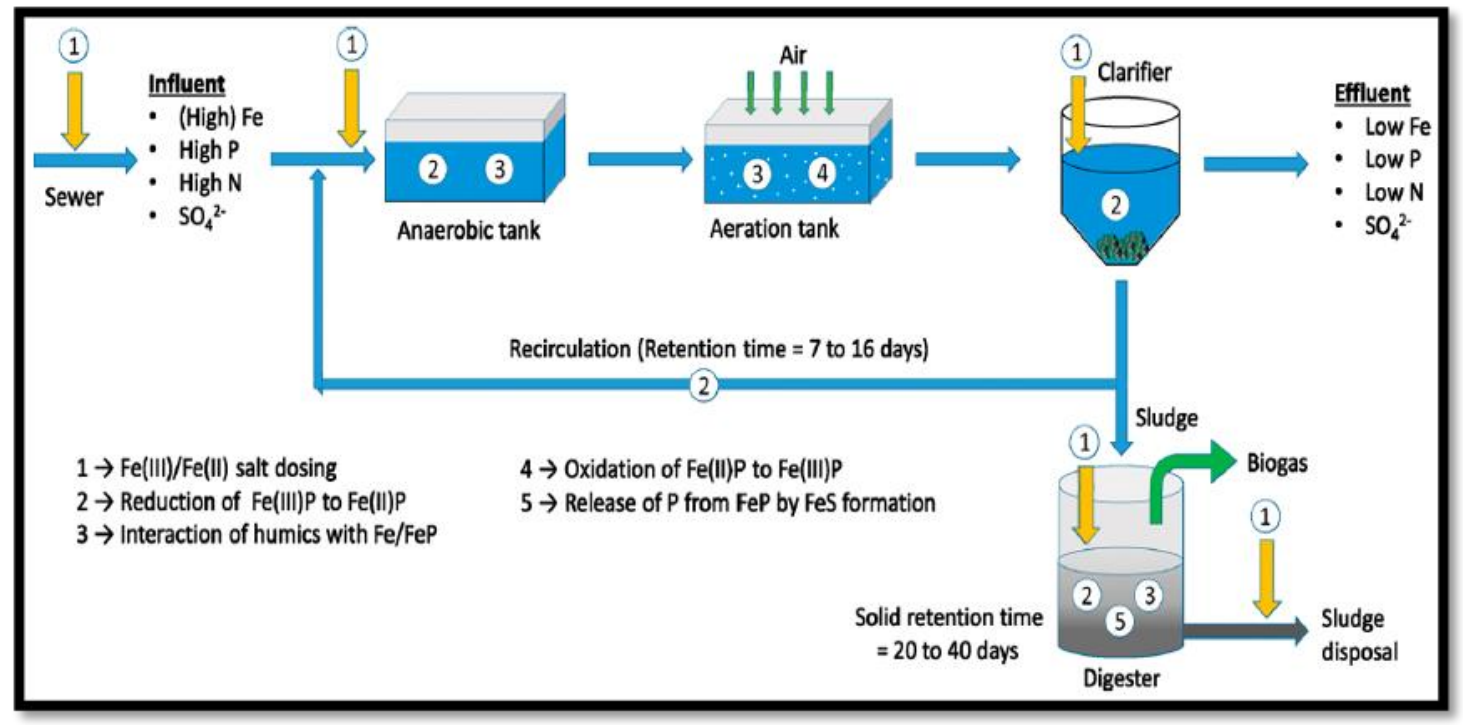

Fig. 1 - Possible Fe and P interactions at different stages in WWTP (Wilfert et al., 2015)

$\mathrm{Ca}^{2+}$ salts are also generally used as coagulants. About $60-90 \%$ of the phosphorus in the sewage can be removed in the aeration tank of activated sludge sewage treatment plants which are activated under conditions of high dissolved oxygen and high $\mathrm{pH}$ levels. The high rate of aeration in hardwater causes $\mathrm{CO}_{2}$ produced by the biodegradation of 
wastes to be swept out and this further increases the $\mathrm{pH}$ level (Wilfert et al., 2015): The reactions which occur between calcium and phosphate ions can be explained using the following equation:

$$
5 \mathrm{Ca}^{2+}+3\left(\mathrm{HPO}_{4}\right) 2^{-}+\mathrm{H}_{2} \mathrm{O} \rightarrow \mathrm{Ca}_{5} \mathrm{OH}\left(\mathrm{PO}_{4}\right)^{3}(s)+4 \mathrm{H}^{+}
$$

The precipitated hydroxyapatite as well as other forms of calcium phosphate are combined with the sludge floc (Manahan, 2009). In the chemical process for phosphorus removal, the Water Environment Federation (2011) stated that the effectiveness of phosphorus removal is dependent on two factors; the chemical equilibrium between the phosphorus liquid and solid phases and the productivity of the solid (formed) removal process, which is a more dominant factor. Next, chemical precipitation using lime is the earliest method applied for phosphorus removal (Water Environment Federation, 2011). This method can remove almost 90-95\% of phosphate following the reaction:

$$
5 \mathrm{Ca}(\mathrm{OH})_{2}+3 \mathrm{H}_{2}\left(\mathrm{PO}_{4}\right)^{2-} \rightarrow \mathrm{Ca}_{5} \mathrm{OH}\left(\mathrm{PO}_{4}\right)^{3}(s)+3 \mathrm{H}_{2} \mathrm{O}+6 \mathrm{OH}^{-}
$$

Coagulation-flocculation is not easily controlled and produces a large volume of sludge, which causes additional problems (Water Environment Federation, 2011) which require the attention of operating personnel at all times. Hence, this method is less applicable in small communities who prefer minimal wastewater treatment maintenance (Crites $e t$ al., 2016). As known, with reference to conventional activated sludge plant, phosphorus removal by chemical precipitation may be obtained by adding chemicals in the primary settling tank (pre-precipitation), directly to the biological reactor (simultaneous precipitation) and in a subsequent stage after the secondary clarifier (postprecipitation). The chemicals most frequently used are $\mathrm{Al} / \mathrm{Fe}$ salts or lime. With the former, phosphorus precipitates as hydroxyphosphate (Crites et al., 2016). Chemical precipitation can effectively sequester P from effluent. This approach involves the addition of soluble salts (aluminium sulphate, ferric chloride or calcium hydroxide) to wastewater. The dissolved cations precipitate with orthophosphate as an insoluble sludge. However, chemical dosing is expensive and the disposal of P-rich sludge from wastewater treatment is a problem, as noted by Parsons and Smith. While recent efforts have been made to recover the P bound in water treatment sludges using acid ( $\mathrm{H} 2 \mathrm{SO} 4)$ and alkaline $(\mathrm{NaOH})$ reagents, the high costs and environmental impacts associated with the use of such aggressive chemicals is a concern (Zhao et al., 2017).

\subsection{Biological Removal of Phosphorus}

Primarily, Enhanced Biological Phosphorus Removal (EBPR) which normally occurs during the activated sludge process (secondary treatment) depends on the selection and proliferation of a specific microbial population called phosphate accumulating organisms (PAOs) which may store orthophosphate in excess of their biological growth requirements (Water Environment Federation, 2011).

The EBPR process consists of an anaerobic zone followed by an aerobic zone. In the anaerobic zone, PAOs will disperse certain organic compounds in the form of volatile fatty acids (VFAs) for intracellular storage, also known as polyhydroxyalkanoates (PHA). The energy attained for this process comes from the hydrolysis of polyphosphate molecules which are stored by the PAOs. Hence, phosphorus, magnesium and potassium ions are released to the anaerobic medium. In addition, the anaerobic zone provides a modest advantage for PAOs. They remove almost all organic substrates in the anaerobic zone, leaving little or no organic substrates for other organisms in the aerobic zone (Yang et al., 2019).

In the meantime, the PAOs break down the stored PHA as a source of food in the aerobic zone. The oxidation of PHA discharges energy where it can be used to take up all of the orthophosphate released in the anaerobic zone as well as additional phosphorus in the influent to renew the stored polyphosphate pool (Yang et al., 2019). PAOs may take up excess phosphorus compared to their metabolic requirements because the energy released by PHA oxidation is larger compared to the energy for PHA storage (Water Environment Federation, 2011). This EBPR process can eliminate more than $85 \%$ of phosphorus from wastewater (Ramasahayam et al., 2014).

\subsection{Filter media for phosphorus removal}

According to Klimeski et al, (2012), the P retention is suggestively affected by the chemical composition of the adsorbents, its particle size and $\mathrm{pH}$ related effects during operation. Moreover, the chemical composition of the materials used should have a high composition of metal oxides including Calcium $(\mathrm{Ca})$ and $\operatorname{Iron}(\mathrm{Fe})$ oxides where these materials are the foremost contributors for sites for phosphorus removal by adsorption and precipitation (Praven et al., 2016). Vohla et al. (2016) pointed out that most of the great filter media studied for phosphorus removal are high in $\mathrm{CaO}$ content and had a $\mathrm{pH}$ level greater than 7 . Thus, presence of $\mathrm{Ca}$ ions were principally important constituents for choosing filter media for phosphorus removal.

Besides, other important factors need to be considered as well while choosing the best filter media such as saturation time, availability at a local level, content of heavy metals, and the recyclability of filter materials (Hamdan \& 
Mara, 2013). In order to obtain a very reliable filter medium for phosphorus removal, selection of filter media should be done very carefully (Vohla et al., 2016). A variety of filter materials have been studied for phosphorus removal. These materials normally contain high calcium, iron, and aluminium content. Potential filter materials can be categorised as naturally derived materials, industrial waste products, and manufactured materials. The results from different materials used for removing phosphorus are shown in Table 1.

Johansson (2013) studied limestone as a filter medium for phosphorus removal. Limestone has the potential to remove phosphorus due to high calcium content. It is composed typically of the mineral calcite $\left(\mathrm{CaCO}_{3}\right)$. Sometimes it is virtually pure calcite, but most limestones are filled with lots of other minerals and sand. Calcite is derived mostly from the remains of organisms such as clams, brachiopods, crinoids and corals that contribute to phosphorus removal efficiency. In the meantime, Razari (2016) examined phosphorus removal using sand amended with biochar as a filter medium. The results show that the removal of total phosphorus ranged between $42 \%$ to $91 \%$. However, sand amended with biochar was less effective in removing total phosphate.

Temporarily, He et al., (2017) investigated the performance of fly ash as a substrate. When fly ash was used as a substrate, phosphorus removal was $83 \%$. Filter material such as blast furnace slag (BFS) is a porous, non-metallic coproduct manufactured in the iron and steel industry. Based on the experiments carried out by (Hamdan and Mara, 2013), phosphorus was initiated on the BFS surface of each sample. The concentration of phosphorus accumulating on the BFS surface over a two-month period was approximately $1.59 \pm 0.68 \%$ by weight. The adsorbed phosphorus on the BFS surface gradually increased over a 6-month period of the trial, which is $6.5 \%$. Thus, the dominant mechanisms of phosphorus removal in the filter involved the adsorption onto the BFS surface and the adsorption of phosphorus onto amorphous $\mathrm{Ca}, \mathrm{Al}$, and Fe oxides of the BFS surface (Hamdan \& Mara, 2013). There are various benefits in using recycled concrete aggregate (RCA) as a filter media as it is easy to prepare a blend of metal oxides. It might increase the phosphorus removal efficiency when recycled concrete is used as a substrate in wastewater treatment. For example, Almir \& Francis (2019) designed a column study to remove phosphorus. It was found that the recycled concrete and mortar resulted in a phosphorus reduction of $93.20 \%$. Therefore, a higher percentage of phosphorus removal can be achieved through the use of recycled concrete.

Table 1 - Materials used as filter media for phosphorus removal

\begin{tabular}{|c|c|c|c|c|}
\hline Made & Material & Description of study & Phosphorus removal & References \\
\hline \multirow[b]{2}{*}{ Natural } & Limestone & $\begin{array}{c}\text { Treating wastewater } \\
\text { mechanically }\end{array}$ & $50 \%$ removal & $\begin{array}{l}\text { Johanson, } \\
(2013)\end{array}$ \\
\hline & Sand & $\begin{array}{l}\text { Column study using } \\
\text { sand amended with } \\
\text { biochar }\end{array}$ & $42-91 \%$ removal & $\begin{array}{l}\text { Razari et al., } \\
\text { (2016) }\end{array}$ \\
\hline \multirow{3}{*}{$\begin{array}{l}\text { Industrial by- } \\
\text { products }\end{array}$} & Fly ash & $\begin{array}{l}\mathrm{CW} \text { for eutrophic } \\
\text { river }\end{array}$ & $83 \%$ removal & $\begin{array}{l}\text { He et al., } \\
\text { (2017) }\end{array}$ \\
\hline & $\begin{array}{l}\text { Blast furnace } \\
\text { slag }\end{array}$ & Field study & $\begin{array}{c}\text { The adsorbed } \\
\text { phosphorus on BFS } \\
\text { surface increased by } \\
6.5 \% \text { over a } 6 \text {-month } \\
\text { period }\end{array}$ & $\begin{array}{l}\text { Hamdan and } \\
\text { Mara, (2013) }\end{array}$ \\
\hline & $\begin{array}{c}\text { Recycled } \\
\text { concrete and } \\
\text { mortar }\end{array}$ & $\begin{array}{l}\text { Column study to } \\
\text { remove phosphorus }\end{array}$ & $93.20 \%$ & $\begin{array}{c}\text { Almir \& } \\
\text { Francis (2019) }\end{array}$ \\
\hline \multirow{2}{*}{$\begin{array}{l}\text { Man-made } \\
\text { materials }\end{array}$} & Filtra-P & $\begin{array}{l}\text { Column study using } 5 \\
\mathrm{mg} \mathrm{P} / \mathrm{dm}_{3} \text { tap water }\end{array}$ & $98.2 \%$ removal & $\begin{array}{c}\text { Gustafsson } e t \\
\text { al., (2018) }\end{array}$ \\
\hline & Filtralite- $\mathrm{P}^{\mathrm{TM}}$ & Field study & $40 \%$ removal & $\begin{array}{l}\text { Adam et al., } \\
\quad(2016)\end{array}$ \\
\hline
\end{tabular}

Meanwhile, Filtralite are man-made materials. Filtralite is identified as a lightweight product in Norway and it has been the subject of many experiments in laboratories as well in fieldwork. Filtralite is made of natural a mineral clay called illite with natural additives (Adam et al., 2016). It is made by running palletised clay aggregates through a rotary kiln at $1200 \circ \mathrm{C}$. Jenssen and Krogstad, (2016) found that Filtralite has a high pH (10) and high calcium and magnesium content that affect phosphorus removal efficiency. Their performances are limited by technical problems (clogging) though they demonstrated higher efficiency in terms of phosphorus removal compared to steel slag (Gustafsson et al., 2018). Adam et al., (2016) discovered Filtralite as a substrate for phosphorus removal. After saturation, this material may be used as an alternate fertiliser in agriculture. Among the materials investigated for use as filter media, man-made materials were reported to obtain the highest phosphorus removal capacities of up to $98.2 \%$, followed by industrial byproducts such as fly-ash which removed up to $83 \%$ of phosphorus (Chazarenz et al., 2017). 


\subsection{Conclusion}

A large number of different filter media for potential use for P removal from wastewater have been reviewed. The common of these substrates have been tested in laboratory experiment and also been investigated in field trials in real life condition. Some new and possibly promising materials such as Recycled Concrete Aggregate, Filtra-P and fly-ash with extremely high removal of $\mathrm{P}$ should be evaluated for efficiency of $\mathrm{P}$ removal over longer time. Also, well monitored long-term experiments in full size system are needed. All these material has higher Calcium content. The man-made materials which is Filtra-P has the highest percentage removal of phosphorus which is $98.2 \%$ and follows by the industrial by product which is recycled concrete and mortar $93.2 \%$ percentage removal of phosphorus.

\section{Acknowledgement}

The authors gratefully to acknowledge the Ministry of Education and Universiti Tun Hussein Onn Malaysia for providing the financial support through the Fundamental Research Grant Scheme (1618) and Geran Penyelidikan Pascasiswazah (H546).

\section{References}

[1] P. Praveen, K.C. Loh (2016). Nitrogen and phosphorus removal from tertiary wastewater in an osmotic membrane photobioreactor, Bioresour. Technol. 206, 180-187

[2] Adam, K., Sovik, A. K., Krogstad, T. (2016). Sorption of phosphorus to Filtralite-PTM - The effect of different scales. Water Research, 40, 1143-1154

[3] Akpor, O. B., Muchie, M. (2017). Environmental and public health implications of wastewater quality. African Journal of Biotechnology, 10(13), 2379-2387.

[4] Almir.S, \& Francis.R.S. (2019). Concretes and mortars recycled with water treatment sludge and construction and demolition rubble. Water Research, 40, 1143-1154

[5] Altundogan, H. S., \& Tumen, F. (2016). Removal of Phosphates from aqueous solutions by using Bauxite. I: Effect of $\mathrm{pH}$ on the adsorption of various phosphates. Journal of Chemistry Technology Biotechnol., 77

[6] Bowman, M., Chamber, P. T., \& Schinder, D. W. (2018). Constraints on algae response to nutrient addition in river. River Research and Application, 23, 8-12

[7] C. Yang, C. Qiu, C. He, Z. Hu, W. Wang (2019). Influence of aluminium accumulation on biological nitrification and phosphorus removal in an anoxic-oxic membrane bioreactor, Environ. Sci. Pollut. Res., 26, 28127-28134

[8] Chazarenz, M., Surasyh, H., \& Deskon, S. (2017). Biological phosphorus removal process for wastewater treatment. International Conference of Science, 27

[9] Dodds, W. K., \& Smith, V. H. (2016). Nitrogen, phosphorus, and eutrophication in streams. Inland Waters, 6, $155-164$

[10] Gustafsson, S., Jonidi, A., Rafiee, M., \& Rezaei, R. (2018). Separate and simultaneous removal of phenol, chromium, phosphorus and cyanide from aqueous solution by coagulation /precipitation by filtra-P: Mechanisms and theory. Chemical Engineering Journal, 253, 251-257

[11] Hamdan, R., \& Mara, D. (2013). Study of in-filter phosphorus removal mechanisms in an aerated blast furnace slag. International Journal of Research in Engineering and Technology, 2(8), 130-136

[12] Han, S. B., Yan, L., Kong, H. N., Liu, Z. M., Wu, D. Y., Hu, Z. B. (2016). Treatment efficiencies for constructed wetlands for eutrophic landscape river water. Pedosphere, 17, 522-528

[13] He, S. B., Yan, L., Kong, H. N., Liu, Z. M., Wu, D. Y., Hu, Z. B. (2017). Treatment efficiencies for constructed wetlands for eutrophic landscape river water. Pedosphere, 17, 522-528

[14] Henze, D. \& Ledin, C. (2018). Parameter in domestic wastewater by using limestone. Journal of water research, 11(3)

[15] Jenssen, P.D., Krogstad, T. (2016). Design of constructed wetlands using phosphorus adsorbing lightweight aggregate. Advance in ecological science, WIT Pres, Boston, (11), 259-272

[16] Johansson, L. (2013). Substrates for phosphorus removal potential benefit for wastewater treatment. Water resources., 40, 23-36

[17] Keeley, J., Smith, A., Judd, S., \& Jarvis, P. (2016). Acidified and ultrafiltered recovered coagulants from water treatment works sludge for removal of phosphorus from wastewater. Journal of Water Research, 88

[18] Khiewwijit, R. (2016). New wastewater treatment concepts towards energy saving and resource recovery. Wageningen University. Master Thesis

[19] Klimeski, A., Chardon, W. J., Turtola, E., \& Uusitalo, R. (2012). Potential and limitations of phosphate retention media in water protection: A process-based review of laboratory and field-scale tests. Agricultural and Food Science, 21, 206-223

[20] Morse, G. K., Brett, S. W., Guy, J. A., \& Lester, J. N. U. (2018). Review: Phosphorus removal and recovery technologies. The Science of the Total Environment, 212, 69-81 
[21] Ramasahayam, S., Guzman, L., Gunawan, G., \& Viswanathan, T. (2015). A comprehensive review of phosphorus removal technologies and processes. Journal of Macromolecular Science Part A, 51(6), 538-545

[22] Rozari, P. De, Greenway, M., \& Hanandeh, A. (2016). Phosphorus removal from secondary sewage and septage using sand media amended with biochar in constructed wetland mesocosms. Science of Total Environment, 3, $123-133$

[23] Vohla, C., Kõiv, M., \& Mander, Ü. (2011). Filter Materials for Phosphorus Removal from Wastewater in Treatment Wetlands - a Review, Ecological Engineering 37(1), 70-89

[24] Wang, L., Vaccari, D., Li, Y., \& Shammas, N. (2016). Chemical Precipitation. In Physicochemical Treatment Processes (PP 141-197). Totowa, New Jersey: Humana Press

[25] Wilfert, P., Kumar, P. S., Korving, L., Witkamp, G.-J., \& van Loosdrecht, M. C. M. (2015). The relevance of phosphorus and iron chemistry to the recovery of phosphorus from wastewater: a review. Environmental Science \& Technology, 49(16), 9400-9414

[26] Zhao X.H., Zhao Y.Q. (2009). Investigation of phosphorus desorption from P-saturated alum sludge used as a substrate in constructed wetland. Sep. Purif. Technol., 66, 71-75 